\title{
Influence of plasticity on the fatigue lifetime prediction of adhesively bonded joints using the stress-life approach
}

\author{
Vinicius Carrillo Beber ${ }^{1,2^{*}}$, Pedro Henrique Evangelista Fernandes ${ }^{1}$, Juliana Espada Fragato1, \\ Bernhard Schneider ${ }^{1}$ and Markus Brede ${ }^{1}$
}

*Correspondence:

vinicius.carrillo.beber@ifam.

fraunhofer.de

${ }^{1}$ Fraunhofer-Institut

für Fertigungstechnik

und Angewandte

Materialforschung IFAM,

Werkstoffe und Bauweisen,

Wiener Straße 12,

28359 Bremen, Germany

Full list of author information

is available at the end of the article

\begin{abstract}
The use of adhesive bonding for designing lightweight load-bearing components has increased in recent decades. In this paper the influence of plasticity on the lifetime prediction of bonded joints using the stress-life approach was investigated. The adhesive was a toughened epoxy for structural applications. Stress calculations were performed using finite element analysis. Three material models were employed, a linear-elastic model and two elastoplastic models: Von Mises (pressure independent) and DruckerPrager (pressure dependent). Effective stress was calculated using the theory of critical distances. Lifetime predictions were based on $S N$ curves from literature for scarf and single-lap joints at four different temperatures $\left(-35,-10^{\circ} \mathrm{C}, R T,+50^{\circ} \mathrm{C}\right)$. The material properties were acquired from uniaxial tensile quasi-static experiments on bulk adhesive specimens. These experiments showed a reduction in the values of Young's modulus and yield stress with increasing temperature. A model was proposed based on an Arrhenius-type equation in order to fit the yield stress as a function of temperature. The model showed good agreement to the experimental findings. Regarding lifetime predictions (a) the influence of critical distance was higher for single-lap joints than scarf joints and (b) the prediction errors were lower for elastoplastic modelling than linear-elastic modelling, especially for single-lap joints.
\end{abstract}

Keywords: Fatigue, Finite element analysis, Plasticity, Toughened epoxy structural adhesives, Stress-life, SN curve, Lifetime prediction

\section{Background}

The use of adhesive bonding in the design of load-bearing components has increased in recent decades due to the advantages of this joining technique. These advantages include uniform load distribution, enhanced fatigue properties and the ability to join dissimilar materials [1]. These characteristics make adhesives very attractive for lightweight applications in a wide range of industries such as the automotive, aerospace and rail sectors $[2,3]$. In this context, fatigue is one of the main issues to address when designing bonded joints because cyclic loads occur in almost all engineering structures and may cause failure under loads that are considerably smaller than the quasi-static strength of the materials [4]. The influence of temperature is another important factor to be accounted for in the modelling of components due to its effect on the mechanical properties of adhesives

(c) 2016 Beber et al. This article is distributed under the terms of the Creative Commons Attribution 4.0 International License (http:// creativecommons.org/licenses/by/4.0/), which permits unrestricted use, distribution, and reproduction in any medium, provided you give appropriate credit to the original author(s) and the source, provide a link to the Creative Commons license, and indicate if changes were made. 
[5]. Marques et al. [6] presented a review of adhesives for low and high temperature applications. They showed the effects of adhesive shrinkage, thermal expansion and viscoelasticity on the final mechanical properties of bonded joints. Beber et al. [7] studied the effect of temperature on the fatigue behaviour of a toughened epoxy adhesive (same as used in the current investigation) at five different temperatures ranging from -35 to $+80{ }^{\circ} \mathrm{C}$ and found that with increasing temperature the fatigue strength is reduced. Additionally, they modelled parameters of $S N$ curves as a function of temperature using an Arrhenius-type equation. Among the different modelling methods available for bonded joints, the stress-life approach is widely applied for fatigue modelling. In this approach, the prediction of the number of cycles to failure $\left(N_{f}\right)$ is made as a function of the stress amplitude $\left(\sigma_{a}\right)$ with the aid of $S N$ curves, i.e. Woehler plots [4]. Therefore, the stress calculation is an important step for fatigue analysis of bonded joints. The methods for stress calculation can be divided in two main groups: analytical methods (closed formulations) and numerical methods (e.g. finite element analysis, $F E A$ ). The second group is more suitable for complex geometries, especially due to advances in computer-aided simulation which have reduced the calculation times. This has facilitated the modelling of the variation of geometry, loads and material properties. Da Silva and Campilho [8] presented a review of advances in $F E A$, pointing out applications of this method for the modelling of bonded joints using continuum, fracture and damage mechanics. In fatigue design, the consideration of effective stress as the maximum (peak) stress often produces over-conservative predictions, particularly when dealing with inhomogeneous stress distributions. In order to address this matter, Taylor [9] summarised a group of methodologies called the theory of critical distance $(T C D)$, which take into account a characteristic length (i.e. critical distance) in the assessment of the effective stress. Several authors employed the $T C D$ with success for analysis of specimens under quasi-static and/or cyclic loads and involving a wide variety of materials [10-12].

Schneider et al. [13] estimated the lifetime of scarf and single lap joints of structural adhesives using the stress-life approach. The stress calculations were performed using analytical methods and FEA. They applied the TCD and linear-elastic material behaviour. They concluded that the homogeneity of stress distributions in the adhesive layer has an influence on the quality of the lifetime predictions. Frequently, when dealing with joints that present stress peaks, such as single-lap joints, it is possible to reach local stress levels that might cause a plastic response of the material, despite nominal stresses being within the elastic range. The effect of plasticity was already included in early closed formulations from Hart Smith [14] and Crocombe [15]. The consideration of elastoplastic material behaviour can influence calculations in several ways, for example stress peak relief as demonstrated by Hua [16]. Ward [17] gave an extensive review of the yield behaviour of polymers, highlighting the dependence on the hydrostatic component of the stress, in contrast to other materials such as metals. Xu [18] performed FEA calculations using hydrostatic stress dependent elastoplastic material behaviour (DruckerPrager) to model double lap joints under quasi-static loads. The resulting predictions were more accurate than a hydrostatic independent elastoplastic model (Von Mises).

The objective of the present work is to investigate the effect of plasticity on the fatigue lifetime prediction of bonded joints using the stress-life approach. Stress distributions were calculated using FEA. Three material models were employed, one linear-elastic model and 
two elastoplastic models: Von Mises (pressure independent) and Drucker-Prager (pressure dependent). The effective stress was determined using three different critical distances. For each critical distance, three different methodologies of the TCD were applied. Predictions were based on $S N$ curves obtained from the literature [7] involving scarf and single-lap joints (using the same adhesive used in the current investigation) at four different temperatures $\left(-35^{\circ} \mathrm{C},-10^{\circ} \mathrm{C}, R T,+50{ }^{\circ} \mathrm{C}\right]$ under tension-tension cyclic loading with a stress ratio of $R=0.1$. The input material properties for $F E A$ were acquired from quasistatic experiments on bulk adhesive specimens at the same aforementioned temperatures. The adhesive under investigation was a toughened epoxy intended for structural applications. From the experimental findings, a model was proposed based on an Arrhenius-like equation in order to fit the adhesive yield stress as a function of temperature.

This paper is structured as follows; second section describes the methods used in this work: experimental procedures, FEA, material modelling and lifetime prediction procedure. Third section presents the results of the quasi-static tests, the modelling of the adhesive yield stress and the lifetime predictions. Finally, the last section summarises the main conclusions.

\section{Methods}

\section{Fabrication of bulk adhesive specimens}

The adhesive under investigation was a one component toughened epoxy intended for structural applications. In this adhesive the addition of dispersed rubbery particles in an epoxy matrix provides a multiphase microstructure with increased toughness [19]. Further information about the glass transition temperatures and fatigue properties of the adhesive can be found in the work of Beber et al. [7]. Quasi-static properties are available in the work of Schneider et al. [13]. The bulk adhesive specimens were prepared according to ISO EN 527-1 [20]. The first step of fabrication involved the preparation of adhesive sheets of $5 \mathrm{~mm}$ thickness. The sheets were produced by application (using a pneumatic gun) of the adhesive between plasma-treated non-stick plates. Spacers were placed between the plates in order to ensure the desired adhesive thickness $\left(t_{B S}\right)$. After application the sheets were cured in a hot press under a load of $10 \mathrm{kN}$ (Fig. 1a). The curing conditions $\left(180{ }^{\circ} \mathrm{C} / 30 \mathrm{~min}\right)$ were followed, monitored and recorded in order to ensure the quality of the specimens. After curing (Fig. 1b), the adhesive sheets were machined to the geometry shown in Fig. 2.

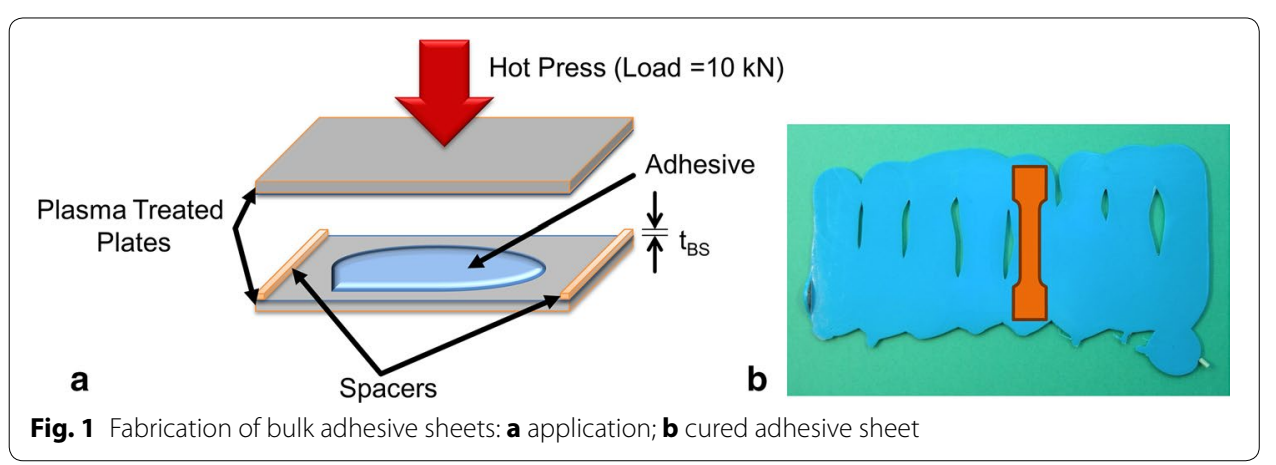




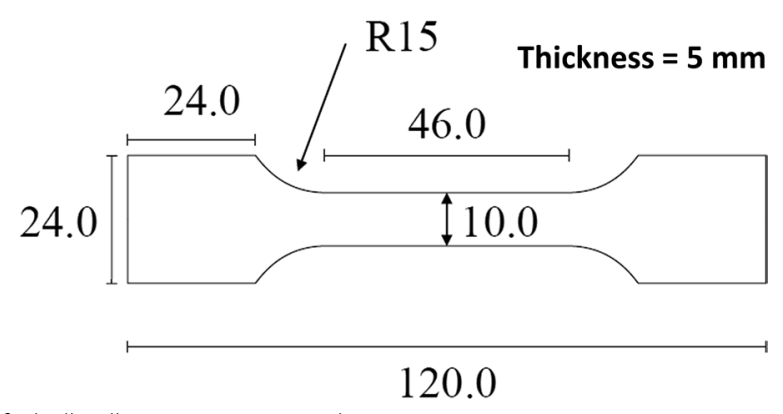

Fig. 2 Geometry of a bulk adhesive specimen—dimensions in $\mathrm{mm}$

\section{Quasi-static experiments}

The bulk adhesive specimens $(B S)$ were tested under uniaxial tension in a servo hydraulic testing machine (MTS Landmark ${ }^{\circledR}$, Eden Prairie, MN, USA) having a maximum load capacity of $50 \mathrm{kN}$. During the tests, the temperature and humidity $(25 \%$ r.h. for $\mathrm{T}>0{ }^{\circ} \mathrm{C}$ ) were controlled. The experiments were conducted under strain control at a rate of $0.00231 / \mathrm{s}$. Figure 3 shows a bulk adhesive specimen clamped in the machine, and the temperature and humidity sensors.

In total 24 tests were performed, i.e. six tests at each temperature $\left(-35^{\circ} \mathrm{C},-10^{\circ} \mathrm{C}, R T\right.$, $+50^{\circ} \mathrm{C}$ ). The tensile stress-strain curves were used to determine the linear-elastic properties [Young's modulus $(E)$ and Poisson's ratio $(v)$ ] and plastic properties of the adhesive. The stress-strain curves were approximated using a polynomial equation. Young's

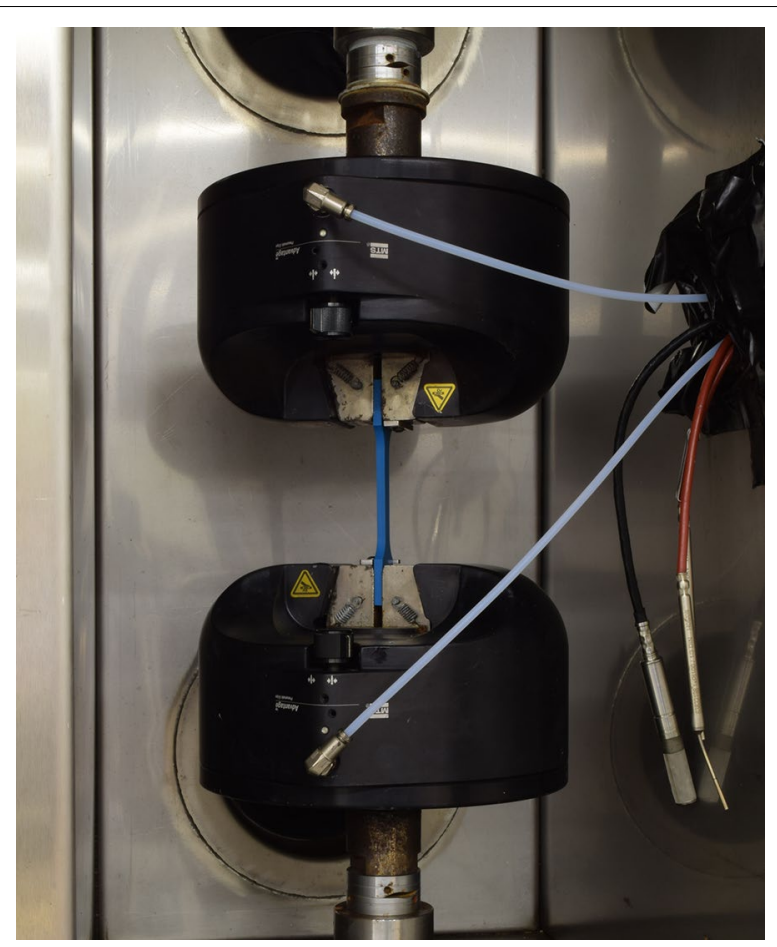

Fig. 3 Quasi-static experiments 
modulus was calculated from the tangent to the curve at the point where deformation started to be plastic. The method of definition of the yield point is described in "Definition of yield stress" section. These properties were employed as input data for FEA calculations of the stress.

\section{FEA-numerical conditions}

The finite element analysis was carried out in order to predict the lifetime of bonded joints and to compare the findings with results found in the literature [7]. Different types of bonded joints were simulated: (i) scarf joints P13, P45 and P56.6; (ii) thick adherend shear joints $(T A S T)$ and (iii) single-lap joints $(S L J)$. The geometry of the specimens is described in Figs. 4 and 5. The models were created using a $2 D$-plane strain consideration to minimise the simulation time. Simulations were performed with the software
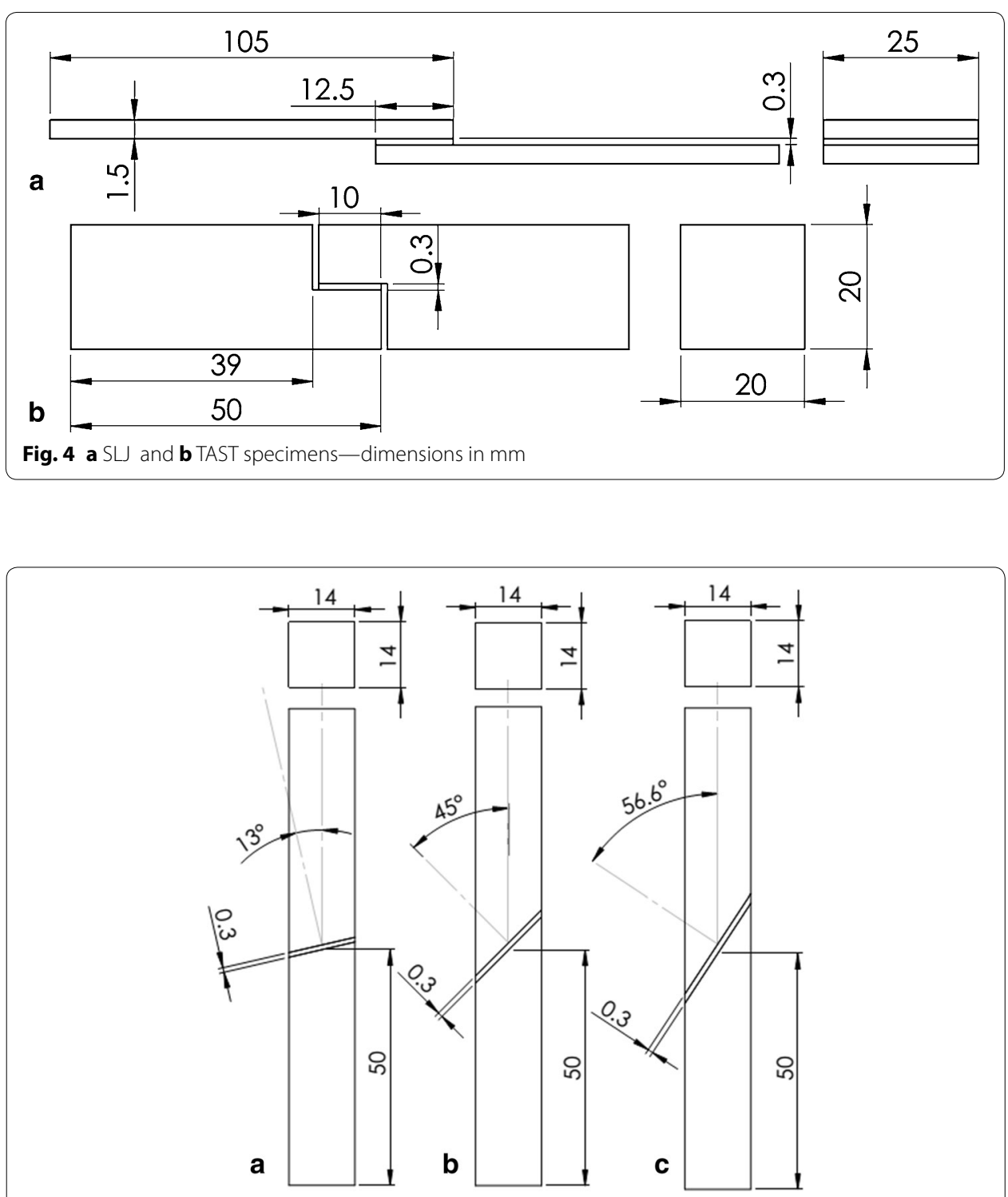

Fig. 5 Scarf joint specimens a P13, b P45 and c P56.6-dimensions in mm 
package Dassault Systèmes Abaqus 6.11-1 ${ }^{\circledR}$. Boundary conditions (Fig. 6) were defined as to reproduce the conditions under fatigue testing: (a) clamping was represented by creating two reference points which were connected to each side of the bonded joints using a rigid body condition; (b) adhesive and adherends were joined using a tie condition; (c) load and degrees of freedom were set in order to reproduce a uniaxial tension loading. The meshing of the adherends and adhesive was performed using CPE8 Elements (8-node biquadratic plane strain quadrilateral). The number of elements in each adhesive layer was $64 \times 8$ (length $\times$ thickness). The mesh of the adherends was refined congruently in the region of bonding.

\section{FEA-material modelling}

The linear-elastic material modelling was based on data obtained experimentally. These properties are summarised in Table 1 which gives mean values and standard deviations at four temperatures.

\section{Definition of yield stress}

For material modelling using the elastoplastic models it was necessary to define a yield stress above which the deformation of the material becomes irreversible. In the case

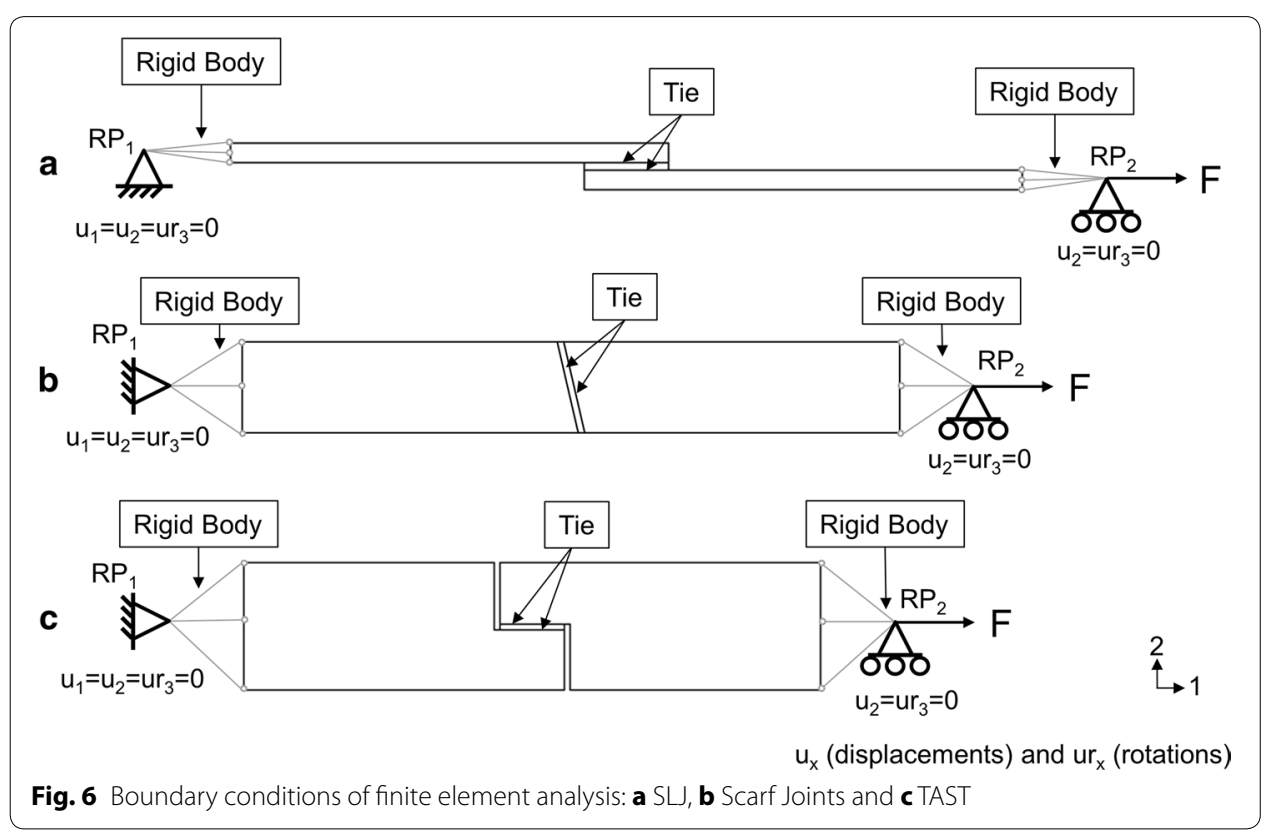

Table 1 Linear elastic properties of the adhesive

\begin{tabular}{lll}
\hline $\boldsymbol{T}\left({ }^{\circ} \mathbf{C}\right)$ & $\boldsymbol{E}(\mathbf{M P a})$ & $\boldsymbol{v}(-)$ \\
\hline-35 & $3546.8 \pm 140$ & $0.428 \pm 0.046$ \\
-10 & $2538.1 \pm 110$ & $0.417 \pm 0.024$ \\
RT & $1571.9 \pm 80$ & $0.402 \pm 0.041$ \\
+50 & $1158.9 \pm 90$ & $0.423 \pm 0.040$ \\
\hline
\end{tabular}


of the toughened epoxy adhesive there was no clear yield plateau in the stress-strain curves. Therefore, the determination of yield stress was based on the work of Christensen [21]. He defines the yield stress $\left(\sigma_{y}\right)$ according to Eq. 1:

$$
\sigma=\sigma_{y}, \quad \text { when } \frac{d^{3} \sigma}{d \epsilon^{3}}=0
$$

For glassy polymers, as in the case of the adhesive under investigation, this point of the maximum second derivative is caused by molecular rearrangement and damage at both molecular and macroscopic levels [21].

The procedure to define the yield stress was performed as follows: (i) the engineering stress-strain curve was transformed into a true stress-strain curve; (ii) the experimental measurements (discrete values) were transformed into continuous equations using a polynomial regression; (iii) the yield stress was defined by 3rd derivation using Eq. 1 . The yield stress results are presented in "Tensile properties and temperature" section.

In order to model plasticity using the finite element models, a description of plastic behaviour of the materials after yielding was necessary. This was done using a plastic potential function, which assumes that the components of the plastic strain increment tensor are proportional to partial derivatives of the plastic potential, which is a scalar function of stress. In this work, it was assumed that the plastic potential function $(g)$ has the same form as the yield function (f), for both Von Mises and Drucker-Prager modelling, in a so-called associated flow. Hence the direction of increment of plastic strain is the same as the normal vector of the yield surface.

\section{Von Mises yield criterion}

The Von Mises yield criterion [22] considers the yield behaviour as pressure-independent, assuming that the yield stresses in simple compression and tension have the same value, so depending only on the deviatoric stress tensor. This criterion is also known as the maximum distortion energy criterion. The yield surface $\left(f_{V M}\right)$ for Von Mises is defined by Eq. 2 :

$$
f_{V M}=q-\sigma_{y}=0
$$

Here $q$ is the Von Mises equivalent stress which is defined in terms of principal stresses $\left(\sigma_{1}, \sigma_{2}, \sigma_{3}\right)$ by Eq. 3:

$$
q=\sqrt{\frac{1}{2}\left[\left(\sigma_{1}-\sigma_{2}\right)^{2}+\left(\sigma_{2}-\sigma_{3}\right)^{2}+\left(\sigma_{1}-\sigma_{3}\right)^{2}\right]}
$$

\section{Drucker-Prager yield criterion}

The Drucker-Prager yield criterion [23] considers the influence of pressure on the yield behaviour of materials and can be interpreted as an extension of the Von Mises yield criterion. The dependence of the yield on the pressure is shown in Fig. 7 for two models: a pressure independent model (Von Mises, VM) and a pressure dependent model (Drucker-Prager, DP):

In this investigation a linear Drucker-Prager model was used. In this model, the yield surface can be described by Eq. 4 [24]:

$$
f_{L-D P}=q-p \cdot \tan (\beta)-\sigma_{y}=0
$$




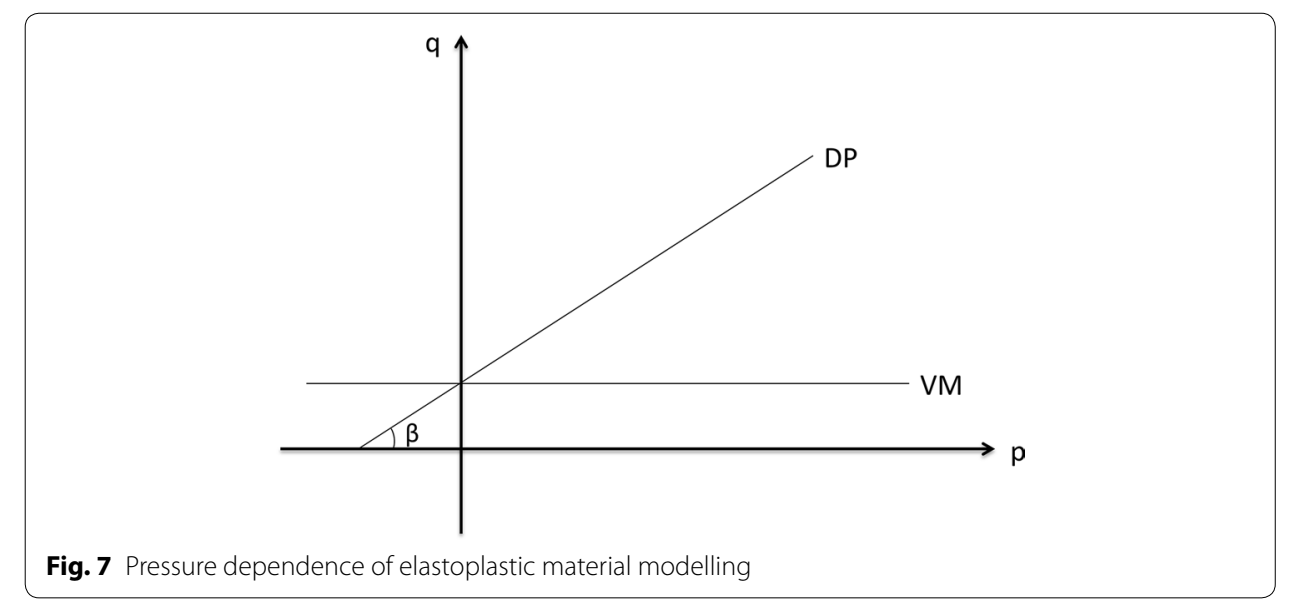

where $p$ is the hydrostatic equivalent stress $\left(p=-\frac{1}{3}\left(\sigma_{1}+\sigma_{2}+\sigma_{3}\right)\right)$ and $\beta$ is the friction angle, a property of the material measured using tensile and compressive tests. In the $F E$ model it is also necessary to define the dilation angle $(\phi)$, but as associated flow was assumed it follows that $\phi=\beta$.

\section{Lifetime calculation procedure}

In the stress-life approach the lifetime prediction of a specimen is done on the basis of a $S N$ curve from another specimen, the so-called base $S N$ curve. Therefore, it was necessary to determine an equivalent stress in order to make $S N$ curves of different specimens comparable, since base $S N$ curves results from experimental tests in which the nominal stress is used. In this work, the maximum principal stress $(s p 3=\max [\sigma 1, \sigma 2, \sigma 3])$ was chosen as the equivalent stress, as has been by other authors for the design of bonded joints [25-27]. Fatigue is a process that often does not just occur locally (hot spot) but rather occurs in a "process zone". In this context, a length parameter in which the process takes place was determined, i.e. a critical distance [28]. Three methodologies of the TCD were used PM (Eq. 5), LM (Eq. 6) and the third methodology (Max) was to define the effective stress as the maximum value of the stress within the critical distance (Eq. 7). Therefore, the effective stress at each methodology was defined as follows:

$$
\begin{aligned}
& \sigma_{e f f-P M}=\sigma\left(\frac{L}{2}\right) \\
& \sigma_{e f f-L M}=\frac{1}{2 L} \int_{0}^{2 L} \sigma(x) d x \\
& \sigma_{e f f-\operatorname{Max}}=\max _{(0, L)}[\sigma(x)]
\end{aligned}
$$

Three different critical distances were used. The value of the critical distance was normalised $\left(L^{*}\right)$ meaning that the chosen critical distance for each specimen was divided by the adhesive layer length (Eq. 8).

$$
L^{*}=\frac{L}{L_{a d h}}
$$


Here $L_{a d h}$ is the adhesive layer length that changes for each type of specimen and $L$ is the chosen critical distance. The values of $L^{*}$ were $L_{1}=0.03125, L_{2}=0.0625$ and $L_{3}=0.125$. Three material models were applied. Table 2 summarises the variations that were possible for the predictions. In total 27 different combinations of material modelling, critical distance and TCD methodology were applied for each prediction. The lifetime prediction procedure is depicted in Fig. 8.

The procedure was conducted as follows:

(a) A base $S N$ curve was chosen.

(b) Base $S N$ curve: the nominal stress amplitudes for lifetimes of $N=\left(10^{3}, 10^{4}, 10^{5}, 10^{6}\right)$ were selected.

(c) Base $S N$ curve: those nominal stress amplitudes were used as input data for a $F E A$ model of the base $S N$ specimen.

(d) Base $S N$ specimen: for each nominal stress amplitude, the stress distribution in the centre of the adhesive layer was calculated.

Table 2 Variations applied for the predictions

\begin{tabular}{lll}
\hline Material model & Normalised critical distance & Methodology \\
\hline Linear-elastic & $L_{1}=0.03125$ & $P M$ \\
Von mises & $L_{2}=0.0625$ & $L M$ \\
Drucker-Prager & $L_{3}=0.125$ & Max \\
\hline
\end{tabular}

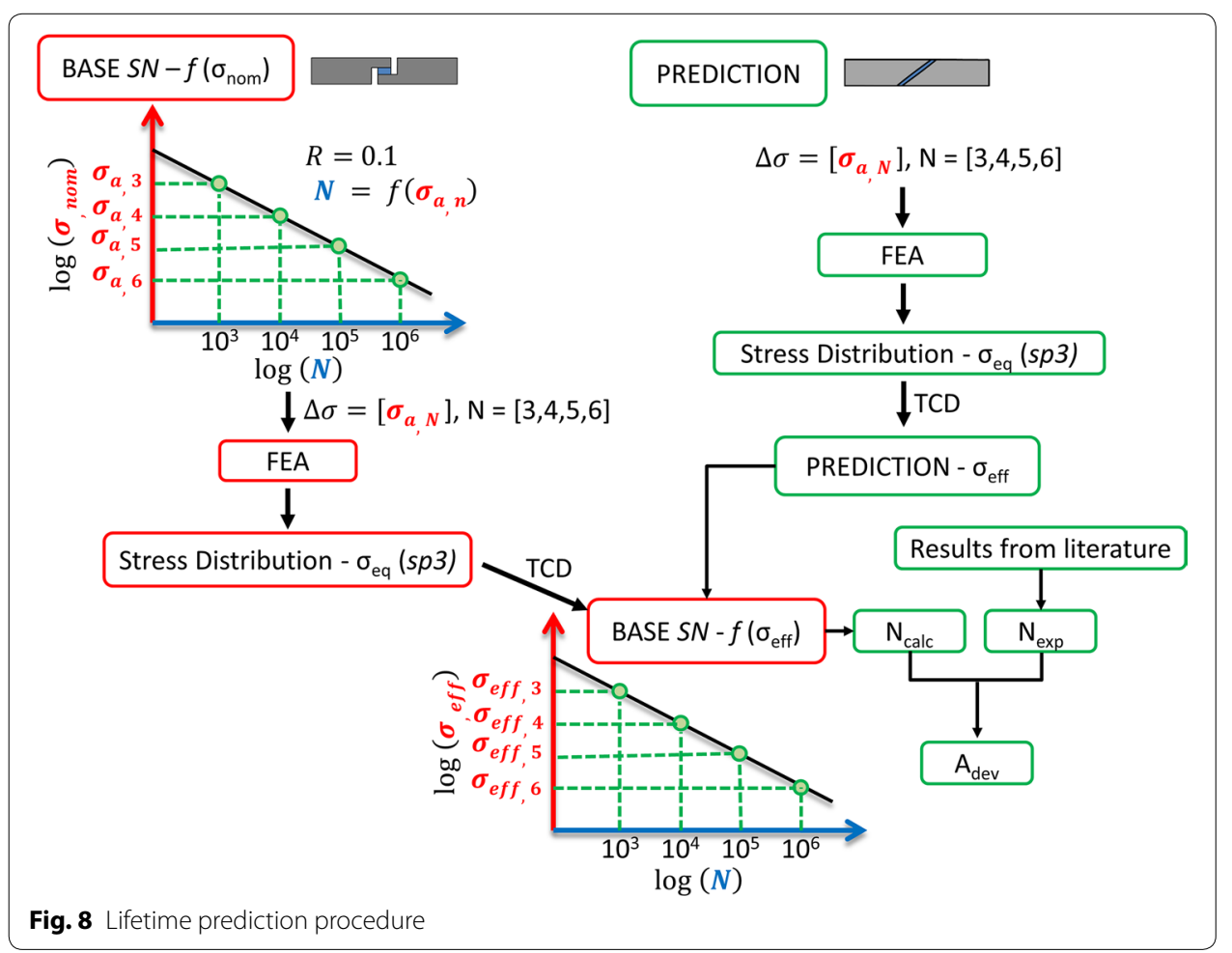


(e) Base $S N$ specimen: a combination of critical distance and TCD methodology was chosen, and from the stress distribution the effective stresses for $N=\left(10^{3}, 10^{4}, 10^{5}\right.$, $10^{6}$ ) were determined.

(f) The base $S N$ curve was transformed from nominal stress into an effective stress $S N$ curve.

(g) Predicted specimen: nominal stress amplitudes for lifetimes of $N=\left(10^{3}, 10^{4}, 10^{5}\right.$, $10^{6}$ ) were selected.

(h) Predicted specimen: for each nominal stress amplitude, the stress distribution in the centre of the adhesive layer was calculated.

(i) Predicted specimen: using the same combination of critical distance and TCD methodology as the base $S N$ curve, the effective stresses were determined.

(j) Predicted specimen: the calculated effective stresses were used in the related transformed base $S N$ curve, the predicted number $\left(N_{\text {calc }}\right)$ of cycles was determined.

(k) $N_{\text {calc }}$ was compared to experimental results from the literature $N_{\text {exp }}$.

(l) The deviation factor $\left(A_{d e v}\right)$ was calculated on the basis of $N_{\text {calc }}$ and $N_{\text {exp }}$.

$A_{d e v}$ can be calculated using Eq. 9.

$$
A_{\text {dev }}=10^{\frac{1}{n} \sum_{i}^{n} \mid \log N_{i}(\text { calc })-\log N_{i}(\exp ) \mid}
$$

Finally, an analysis was carried out to evaluate the influence of: base $S N$ curve, critical distance, TCD methodology ( $P M, L M$ or $M a x$ ) and material modelling, i.e. which combination would give the best predictions (the smallest $A_{d e v}$ ).

\section{Results and discussion}

\section{Tensile properties and temperature}

The tensile stress-strain curves revealed an influence of temperature on the Young's modulus $(E)$ of the adhesive (Fig. 9), where $E$ diminished with increasing temperature. On the other hand, the Poisson's ratio $(v)$ results showed no noticeable trend related to temperature.

Representative tensile stress-strain curves as a function of temperature are illustrated in Fig. 10 from which the yield stress $\left(\sigma_{y}\right)$ was calculated as described in "Definition of yield stress" section. As shown in Fig. 10, the strain increased with increasing temperature. However, the ultimate strength decreased when the temperature increased.
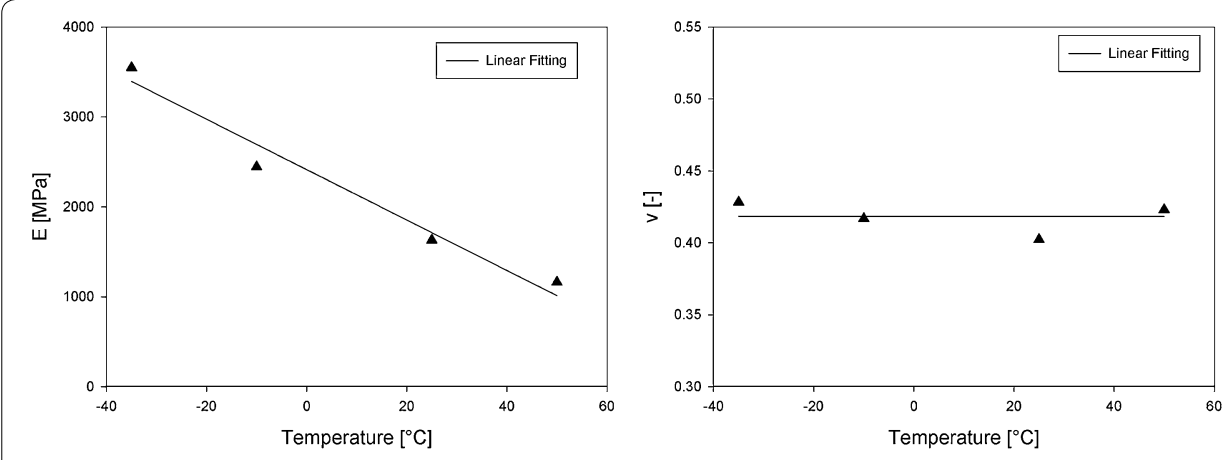

Fig. 9 Tensile properties as a function of temperature-E (left) and $v$ (right) 


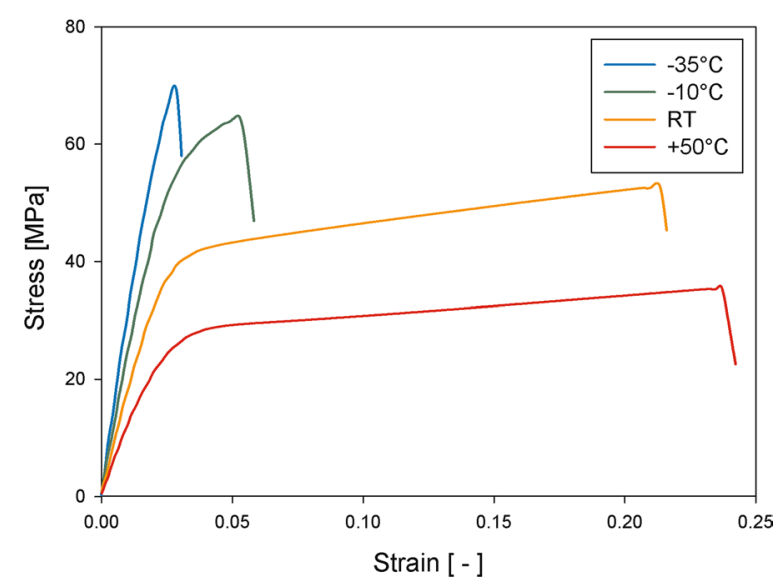

Fig. 10 Representative tensile stress-strain curves

Several studies on glassy polymers [29-31] have demonstrated the temperature dependence of the yield stress. In the present work, a model based on an Arrhenius-type equation was proposed for modelling the yield stress as a function of the temperature. This approach was taken based on consideration of yielding as a thermally activated process, as assumed in earlier studies [32,33]. Equation 10 shows the equation used for the modelling:

$$
\log \left(\sigma_{y}\right)=\log A-B \log \left(\frac{1}{T}\right)
$$

The yield stresses obtained this way were fitted using the proposed model. The result of the fitting process is depicted in Fig. 11.

The proposed model showed good agreement with the experimental results (maximum error of $13 \%$ ), which supports the assumption of yielding as a thermally activated process for the adhesive under investigation.

\section{Lifetime calculation}

Lifetime predictions were conducted for scarf joints (P13 and P56.6) and single-lap joints $(S L J)$. Scarf joints present an almost homogeneous stress distribution (HSD), while single-lap joints and thick adherend shear test joints have a very inhomogeneous stress distribution (ISD). Figure 12 demonstrates this (in) homogeneity of all specimens through the generic stress distributions, assuming a linear-elastic material behaviour. In this chart, maximum principal stresses and adhesive layer lengths were normalised.

Table 3 lists the specimens for which the predictions were performed and the base $S N$ curves used to each lifetime prediction.

The predicted lifetimes were compared with experimental results obtained from Beber et al. [7]. The objective was to determine which combination of base $S N$ curve, material modelling, critical distance length and TCD methodology would give the best quality of prediction for all four temperatures. This was done using $D e v_{\text {Total }}$ which is the sum 


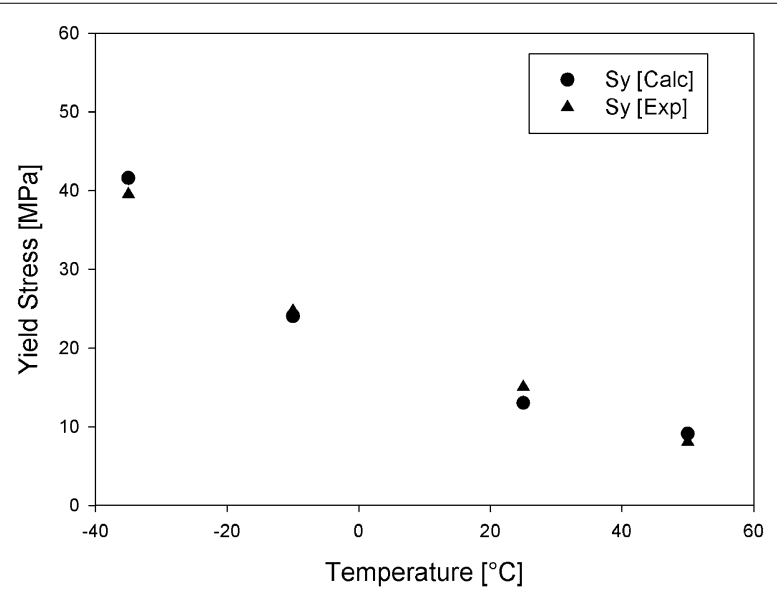

Fig. 11 Yield stress: experimental results and modelling

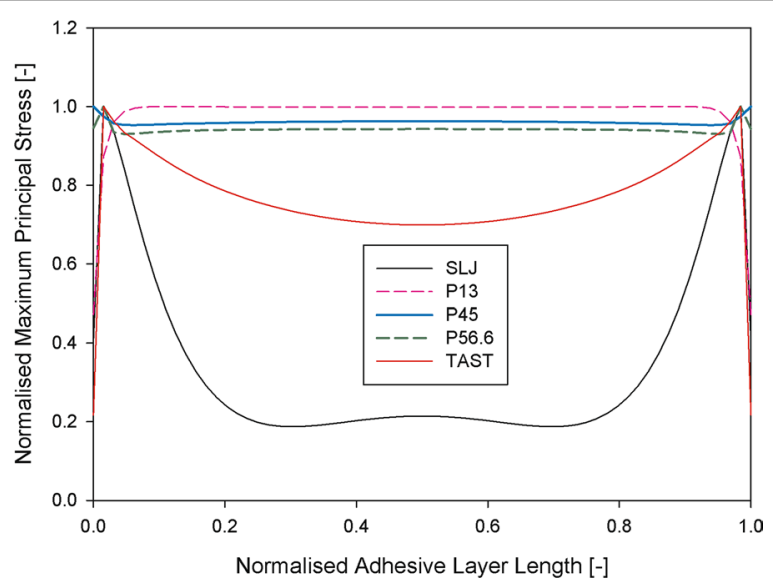

Fig. 12 Generic stress distribution of used specimens

Table 3 Performed predictions

\begin{tabular}{llll}
\hline Pred. & Base & P56.6 & TAST \\
\cline { 2 - 4 } & P45 & $X$ & $X$ \\
\hline P13 & $X$ & - & $X$ \\
P56 & $X$ & $X$ & $X$ \\
SLJ & - & & \\
\hline
\end{tabular}

of the logarithm of each value of $A_{d e v}$ for all temperatures. Equation 11 represents the method for calculation of Dev $v_{\text {Total }}$ :

$$
\text { Dev } v_{\text {Total }}=\sum_{T} \log \left(A_{\text {dev }}\right) \quad \text { for } \quad T=\left[-35^{\circ} \mathrm{C},-10^{\circ} \mathrm{C}, \mathrm{RT},+50^{\circ} \mathrm{C}\right]
$$

when $D e v_{\text {Total }}$ is zero, the prediction had an accuracy of $100 \%$. 


\section{Predictions of scarf joint (P13)}

Figures 13, 14 and 15 show $\operatorname{Dev}_{\text {Total }}$ for predictions of scarf joint (P13): two of them were based on HSD specimens (P45 and P56.6) and one on ISD (TAST) specimens.

The main points to be highlighted are as follows:

- HSD based predictions had smaller Dev $v_{\text {Total }}$ than ISD based ones.

- For HSD based predictions the major differences were due to the TCD methodology rather than material modelling and critical distance.

- For HSD based predictions Dev ${ }_{\text {Total }}$ was maximum for $L M$ and a minimum for PM.

- For ISD based predictions elastoplastic models gave the smallest $D e v_{\text {Total }}$, especially $D P$.

\section{Prediction of scarf joint (P56.6)}

Figures 16 and 17 show predictions for the P56.6 specimens based on HSD (P45) and ISD $(T A S T)$

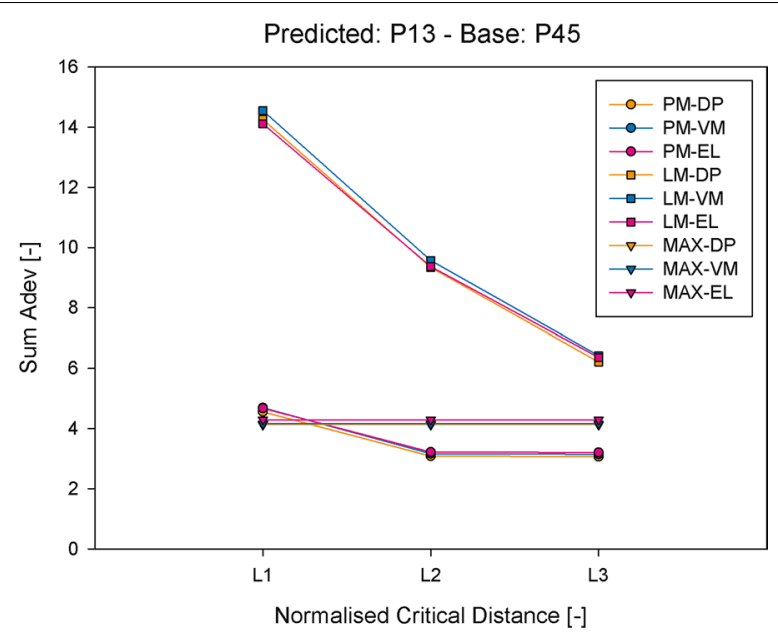

Fig. 13 Prediction of P13 specimen-base: P45

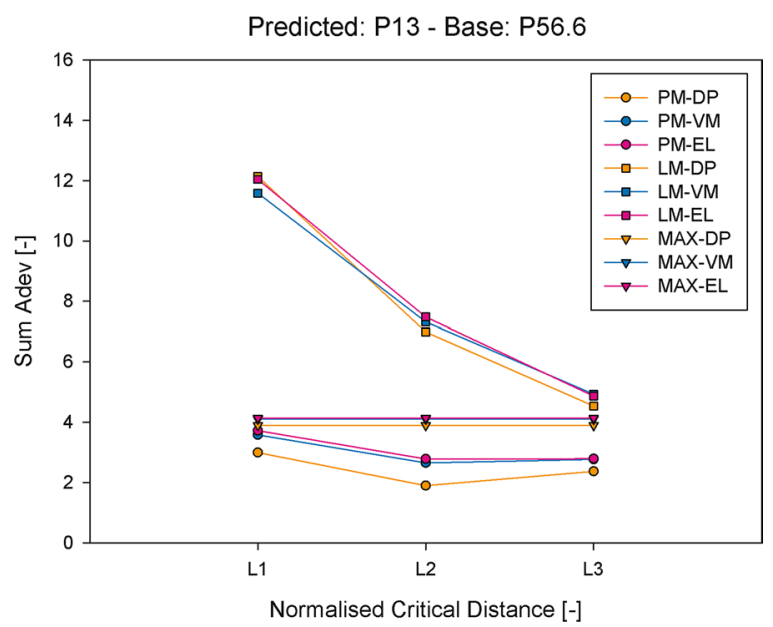

Fig. 14 Prediction of P13 specimen-base: P56.6 


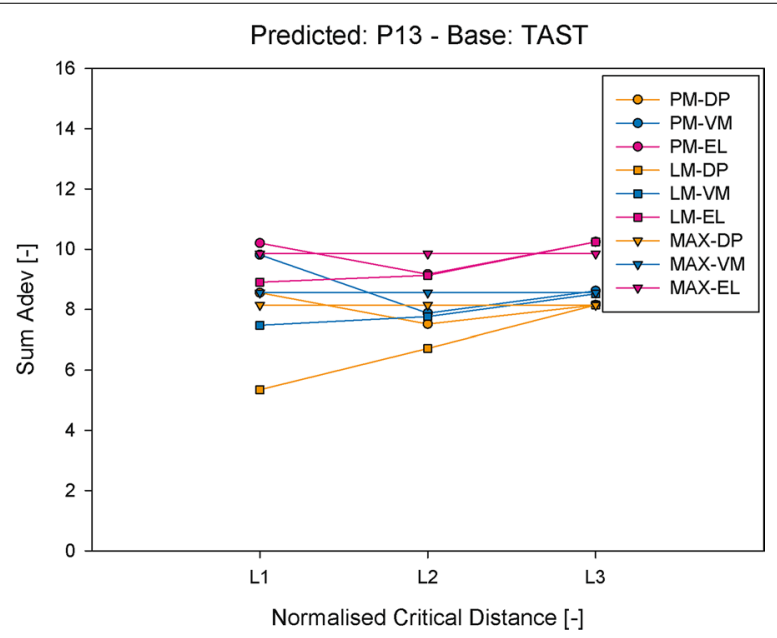

Fig. 15 Prediction of P13 specimen-base:TAST

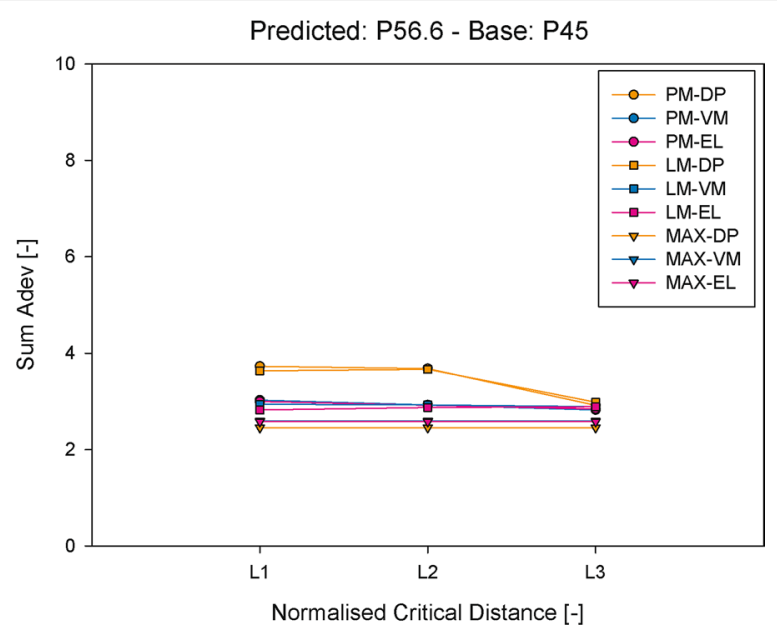

Fig. 16 Prediction of P56.6 specimen—base: P45

The main points to be highlighted are as follows:

- HSD based predictions had smaller Dev $v_{\text {Total }}$ than ISD based ones.

- HSD based predictions showed little effect of the chosen critical distance due to the lack of peak stresses.

- ISD based predictions: marked effect of the material modelling and critical distance on $D e v_{\text {Total }}$ due to stress inhomogeneity.

Prediction of single-lap joint (SLJ)

Figures 18 and 19 show predictions for the SLJ specimens based on HSD (P56.6) and ISD (TAST)

The main points to be highlighted are as follows: 


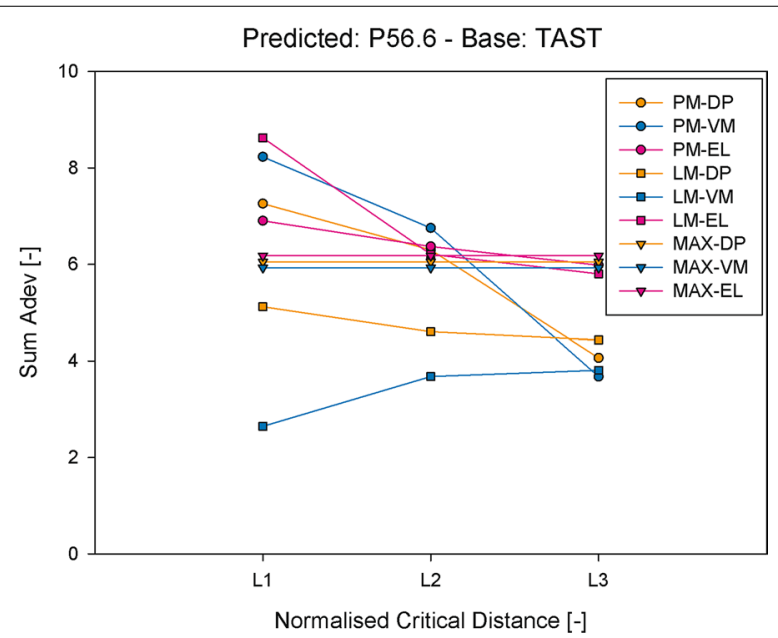

Fig. 17 Prediction of P56.6 specimen—base:TAST

Predicted: SLJ - Base: P56.6

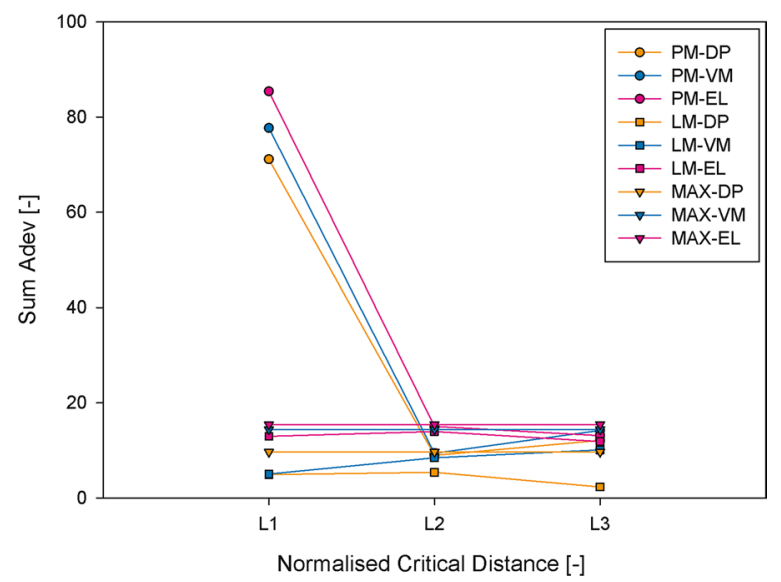

Fig. 18 Prediction of SLJ specimen-base: P56.6

- There was a bigger difference between different combinations of material modelling, critical distance and TCD methodology when compared to P13 and P56.6 predictions.

- The chosen critical distance length had a greater influence when compared to P13 and P56.6 predictions due to the stress inhomogeneity of $S L J$ specimens.

- The best predictions were obtained with elastoplastic models.

- $P M$ based predictions gave the highest values of $D e v_{\text {Total }}$.

- $V M$ and DP predictions gave differing results depending on the chosen base $S N$ curve due to different hydrostatic stress states of each base specimen.

\section{Conclusions}

In this work the influence of plasticity on the lifetime prediction of bonded joints using the stress life approach was investigated. Stress calculations were performed using FEA. 


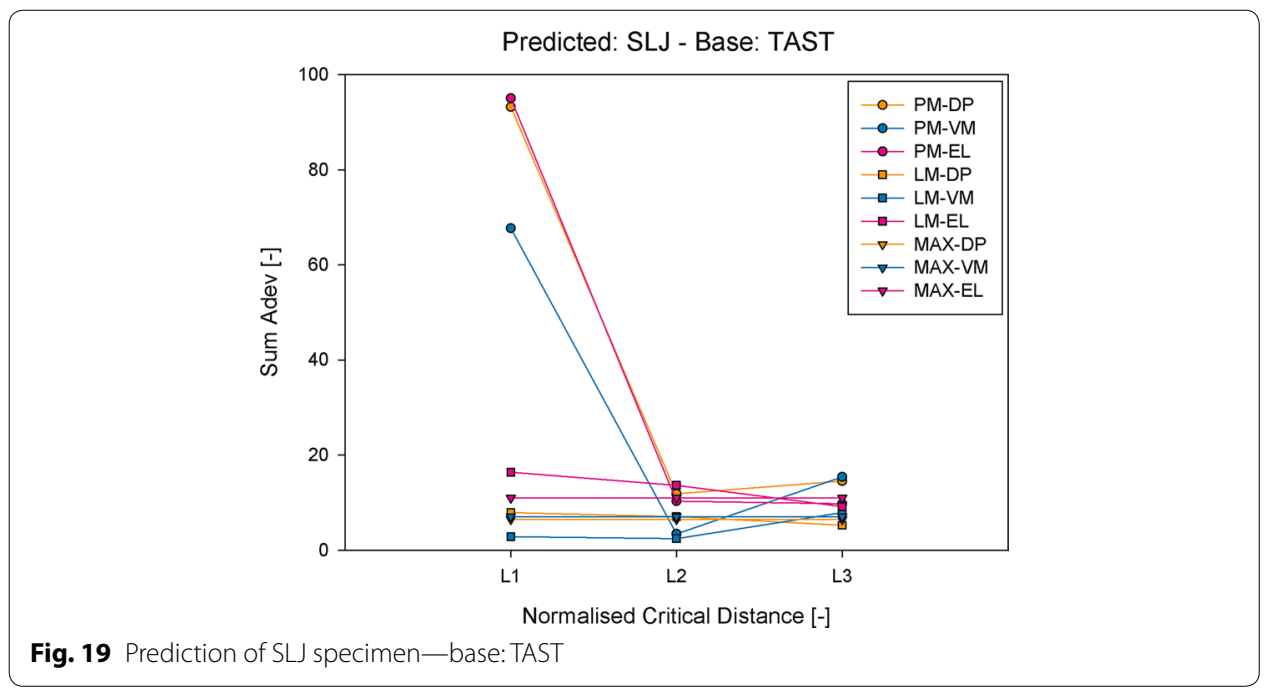

Three material models were employed, a linear-elastic model and two elastoplastic models: Von Mises (pressure independent) and Drucker-Prager (pressure dependent). The effective stress was calculated using the theory of critical distances (TCD). Predictions were based on $S N$ curves obtained from the literature for scarf and single-lap joints at four different temperatures $\left(-35{ }^{\circ} \mathrm{C},-10{ }^{\circ} \mathrm{C}, R T,+50{ }^{\circ} \mathrm{C}\right)$ under tension-tension cyclic loading with a stress ratio of $R=0.1$. The input material properties for FEA were acquired from quasi-static experiments on bulk adhesive specimens. The adhesive was a toughened epoxy intended for structural applications.

The following conclusions can be drawn:

(a) The tensile data obtained from bulk adhesive specimens showed a reduction in the value of Young's modulus and yield stress with increasing temperature.

(b) A model was proposed based on an Arrhenius-type equation in order to fit the yield stress as a function of temperature; the model showed good agreement (maximum error of $13 \%$ ) with experimental findings.

(c) The lifetime predictions for scarf joints were better using base $S N$ curves with almost homogeneous stress distributions.

(d) The prediction errors were overall lower for elastoplastic modelling than for linear-elastic modelling, especially for single-lap joints.

(e) This is likely due to stress inhomogeneity, since the critical distance length had a greater influence on predictions for single-lap joints than scarf joints.

Authors' contributions

Authors VCB, PHEF and JEF performed the finite element analysis. Authors BS and MB conducted the quasi-static experiments. Authors VCB and BS modelled the yield stress using Arrhenius-type equations. All the authors analysed the lifetime predictions and plasticity effects. All authors read and approved the final manuscript.

Author details

${ }^{1}$ Fraunhofer-Institut für Fertigungstechnik und Angewandte Materialforschung IFAM, Werkstoffe und Bauweisen, Wiener Straße 12, 28359 Bremen, Germany. ${ }^{2}$ Fachbereich Produktionstechnik-Maschinenbau \& Verfahrenstechnik, Universität Bremen, Badgasteiner Straße 1, 28359 Bremen, Germany. 


\section{Acknowledgements}

The authors are grateful to the Science without Borders programme (Ciência sem Fronteiras, V.C. Beber 13458/13-2, P.H.E. Fernandes 88888.065050/2013-00, J.E. Fragato 88888.071558/2013-00,) and the programme for Coordination of Improvement of Higher Education Personnel (CAPES-Brazil).

The IGF project $428 \mathrm{ZN} / 2$ of the Forschungsvereinigung automobiltechnik e.V. (FAT) was funded by the AiF under the program for the promotion of joint industrial research and development (IGF) of the Federal Ministry of Economics and Energy based on a decision of the German Bundestag.

\section{Competing interests}

The authors declare that they have no competing interests.

Received: 5 January 2016 Accepted: 22 March 2016

Published online: 04 April 2016

\section{References}

1. Rodríguez RQ, Paiva WP, Sollero P, Rodrigues MRB, Albuquerque EL. Failure criteria for adhesively bonded joints. Int J Adhes Adhes. 2012;37:26-36.

2. Alfano M, Furgiuele F, Leonardi A, Maletta C, Paulino GH. Cohesive zone modeling of mode I fracture in adhesive bonded joints. Key Eng Mater. 2007;348-349:13-6.

3. Grant LDR, Adams RD, da Silva LFM. Experimental and numerical analysis of single-lap joints for the automotive industry. Int J Adhes Adhes. 2009;29(4):405-13.

4. da Silva LFM, Öchsner A. Modeling of adhesively bonded joints. Berlin: Springer; 2008

5. Banea MD, da Silva LFM. The effect of temperature on the mechanical properties of adhesives for the automotive industry. Proc Inst Mech Eng. 2010;224(2):51-62.

6. Marques EAS, da Silva LFM, Banea MD, Carbas RJC. Adhesive joints for low- and high-temperature use: an Overview. J Adhes. 2014;91(7):556-85.

7. Beber VC, Schneider B, Brede M. Influence of temperature on the fatigue behaviour of a toughened epoxy adhesive. J Adhes. 2015. doi:10.1080/00218464.2015.1114927

8. da Silva LFM, Campilho RDSG, editors. Advances in numerical modeling of adhesive joints. SpringerBriefs in applied sciences and technology. Berlin: Springer; 2012.

9. Taylor D. The theory of critical distances: a new perspective in fracture mechanics. Amsterdam: Elsevier; 2007.

10. Taylor D. Applications of the theory of critical distances to the prediction of brittle fracture in metals and non-metals. Paper presented at the 15th European Conference of Fracture - ECF15, Stockholm, August 11-13, 2004.

11. Cicero S, Madrazo V, Carrascal IA. Analysis of notch effect in PMMA using the theory of critical distances. Eng Fract Mech. 2012;86:56-72.

12. Susmel $L$, Taylor $D$. On the use of the theory of critical distances to predict static failures in ductile metallic materials containing different geometrical features. Eng Fract Mech. 2008;75(15):4410-21.

13. Schneider B, Beber VC, Brede M. Estimation of the lifetime of bonded joints under cyclic loads at different temperatures. J Adhes. 2015. doi:10.1080/00218464.2015.1114928

14. Hart-Smith L. Adhesive-bonded single-lap joints. Douglas Aircraft Co., Technical Report NASA-CR-1973-112236, 1973.

15. Crocombe AD, Bigwood DA. Development of a full design analysis elasto-plastic adhesive joint. J Strain Anal 1992;27(4):211-8.

16. Hua Y, Kasavajhala ARM, Gu L. Elastic-plastic analysis and strength evaluation of adhesive joints in wind turbine blades. Compos B Eng. 2013;44(1):650-6.

17. Ward IM. Review: the yield behaviour of polymers. J Mater Sci. 1971;6:1397-417.

18. Xu B. Fracture mechanisms and failure criteria of adhesive joints and toughened epoxy adhesives. Ph.D. Thesis, University of London. 2010:225.

19. Kinloch A. Toughening epoxy adhesives to meet today's challenges. MRS Bull. 2003;28:445-8.

20. Plastics: determination of tensile properties. London: British Standards Institution; 2012. 527-1. ISO.

21. Christensen RM. Observations on the definition of yield stress. Acta Mech. 2008;196(3-4):239-44.

22. von Mises R. Mechanik der festen Körper im plastisch deformablen Zustand. Göttin Nachr Math Phys. 1913;1:582-92.

23. Drucker D, Prager WJ. Soil mechanics and plastic analysis or limit design. Q Appl Math. 1952;10(2):157-65.

24. Dassault Systèmes. Abaqus user's manual 6.11. 2011.

25. Adams RD, Comyn J, Wake WC. Structural adhesive joints in engineering. 2nd ed. London: Chapman and Hall; 1997.

26. Clark JD, McGregor IJ. Ultimate tensile stress over a zone: a new failure criterion for adhesive joints. J Adhes. 1993:42(4):227-45.

27. Harris JA, Adams RA. Strength prediction of bonded single lap joints by non-linear finite element methods. Int J Adhes Adhes. 1984;4(2):65-78.

28. Taylor D. Prediction of fatigue failure location on a component using a critical distance method. Int J Fatigue. 2000;22(9):735-42.

29. Argon AS. A theory for the low-temperature plastic deformation of glassy polymers. Phil Mag. 1973;28(4):839-65

30. Argon AS, Bessonov M. Plastic deformation in polyamides with new implications on the theory of plastic flow of glassy polymers. Phil Mag. 1977;35:917-33.

31. Banea MD, de Sousa FSM, da Silva LFM, Campilho RDSG, Bastos de Pereira AM. Effects of temperature and loading rate on the mechanical properties of a high temperature epoxy adhesive. J Adhes Sci Technol. 2012;25(18):2461-74. 
32. Brereton MG, Croll SG, Duckett RA, Ward IM. Non-linear viscoelastic behaviour of polymers: an implicit equation approach. J Mech Phys Solids. 1974;22(2):97-125.

33. Truss RW, Clarke PL, Duckett RA, Ward IM. The dependence of yield behavior on temperature, pressure, and strain rate for linear polyethylenes of different molecular weight and morphology. J Polym Sci Polym Phys Ed. 1984;22(2):191-209.

Submit your manuscript to a SpringerOpen ${ }^{\circ}$ journal and benefit from:

- Convenient online submission

- Rigorous peer review

- Immediate publication on acceptance

- Open access: articles freely available online

- High visibility within the field

- Retaining the copyright to your article 